\title{
Variations in daily intakes of myristic and $\alpha$-linolenic acids in sn-2 position modify lipid profile and red blood cell membrane fluidity
}

\author{
Henry Dabadie $^{1 *}$, Claude Motta ${ }^{2}$, Evelyne Peuchant $^{3}$, Pascale LeRuyet ${ }^{4}$ and François Mendy ${ }^{5}$ \\ ${ }^{1}$ Service de Nutrition, Hôpital du Haut-Lévêque, Pessac, France \\ ${ }^{2}$ Laboratoire de Biochimie médicale, Faculté de Médecine, Rennes, France \\ ${ }^{3}$ Laboratoire de Biochimie, Hôpital Saint-André, Bordeaux, France \\ ${ }^{4}$ Lactalis Recherche et Développement, Rétiers, France \\ ${ }^{5}$ CNIEL, Paris, France \\ (Received 22 December 2005 - Revised 10 March 2006 - Accepted 20 March 2006)
}

\begin{abstract}
The present study evaluated the effects of moderate intakes of myristic acid (MA), at $1.2 \%$ and $1.8 \%$ of total energy (TE), associated with a $0.9 \%$ TE intake of $\alpha$-linolenic acid (ALA) on lipid and fatty acid profiles and red blood cell membrane fluidity. Twenty-nine monks without dyslipidaemia were enrolled in a 1-year nutritional study in which two experimental diets were tested for 3 months each: diet 1, MA 1.2\% and ALA $0.9 \%$; diet 2, MA $1.8 \%$ and ALA 0.9\%. A control diet (MA 1.2\%, ALA 0.4\%) was given 3 months before diets 1 and 2 . Thus, two different levels of MA $(1.2 \%, 1.8 \%)$ and ALA $(0.4 \%, 0.9 \%)$ were tested. Intakes of other fatty acids were at recommended levels. Samples were obtained on completion of all three diets. For fluidity analysis, the red blood cells were labelled with 16-doxylstearate and the probe incorporated the membrane where relaxation-correlation time was calculated. Diet 1 was associated with a decrease in total cholesterol, in LDL-cholesterol, in triacylglycerols and in the ratio of total to HDL-cholesterol; ALA and EPA levels were increased in both phospholipids and cholesterol esters. Diet 2 was associated with a decrease in triacylglycerols and in the ratios of total to HDL-cholesterol and of triacylglycerols to HDL-cholesterol, and with an increase in HDL-cholesterol; EPA levels were decreased in phospholipids and cholesterol esters. Red blood cell membrane fluidity was increased in both diets $(P<0.0001)$, but the higher increase was obtained with diet 1 , mainly in the oldest subjects. Intakes of myristic acid (1.2\% TE) and ALA ( $0.9 \% \mathrm{TE})$, both mainly in the sn- 2 position, were associated with favourable lipid and $n-3$ long-chain fatty acid profiles. These beneficial effects coexisted with particularly high membrane fluidity, especially among the oldest subjects.
\end{abstract}

Myristic acid: $\alpha$-Linolenic acid: Physiological intakes: Nutritional study: Lipid profile: Membrane fluidity

It has been clearly shown by many epidemiological studies that high saturated fatty acid (SFA) consumption has atherogenic effects and promotes CHD (Keys, 1980; Sandker, 1992; Ascherio et al. 1996). These effects may be mediated to a certain extent by fatty acid-induced changes in serum lipid levels, especially of LDL-cholesterol or HDL-cholesterol, oxidative status, haemostasis, blood pressure and membrane fluidity. The results of these studies have been used to make specific dietary recommendations for the prevention and treatment of CHD leading to a change in eating habits (Krauss et al. 2000). Recent data have, however, shown that: each SFA has its own characteristics, so they should not be considered collectively (Hu et al. 1999); the atherogenicity of a given SFA might depend on the intake of another fatty acid (e.g. linoleic acid (LIA); Clandinin et al. 2000); certain SFA might increase the synthesis of very-long-chain derivate PUFA (Jan et al. 2004).

No study on myristic acid (MA) to date has been conducted with intakes corresponding to those of real life (Tholstrup et al.
1994; Zock et al. 1994; Mensink et al. 2003). It is widely held that, beyond $4 \%$ of total energy (TE), MA leads to an increase in total and LDL-cholesterol by decreasing the activity of the hepatic LDL-cholesterol receptor. Very few studies have been conducted with lower intakes or by taking into consideration the position of the fatty acid on the triacylglycerol. Only the sn-2 position is the bioavailable form that determines its action and protects it from $\beta$-oxidation (Wang \& Koo, 1993). Two previous studies that we conducted in a population of monks (Dabadie et al. 2004, 2005) showed that intakes of MA at $1.2 \%$ and $1.8 \% \mathrm{TE}$ (with intakes of other fatty acids considered appropriate) for 5 weeks were associated with an improved lipid profile and an increase in DHA in cholesteryl esters.

The aim of the present 1-year study was to evaluate the impact of intakes of $1.2 \%$ and $1.8 \% \mathrm{TE}$ of MA associated with intakes of $\alpha$-linolenic acid (ALA) at $0.4 \%$ and $0.9 \% \mathrm{TE}$ on lipid profile and red blood cell (RBC) membrane fluidity. The main source of MA intake was milk, where this fatty acid is in the sn-2 position on the triacylglycerol. 


\section{Subjects and methods}

\section{Subjects}

Thirty-two monks from a Benedictine monastery (Randol Abbey) located in the centre of France were enrolled for a 1 -year interventional study. Twenty-nine of them were followed until the end of the study. They were between 25 and 85 years old (average 57 years), weighed between 53 and $99 \mathrm{~kg}$ (average $71 \mathrm{~kg}$ ) and had a BMI ranging from 28 to $18 \mathrm{~kg} / \mathrm{m}^{2}$ (average $23 \mathrm{~kg} / \mathrm{m}^{2}$ ). None of them was known to have dyslipidaemia (according to National Cholesterol Education Program. Adult Treatment Panel III) before the study, and none was taking any lipid-lowering drug or medication affecting lipid metabolism. Most took a moderate amount of physical activity (e.g. working in the fields, regular walking). Physical activity and lifestyle were kept unchanged during the study. Anthropometric measurements and blood pressure were obtained for each subject at baseline and at the end of the two dietary periods. The protocol and aim of the study were fully explained to the subjects, and their written consent was obtained. The research protocol was approved by the hospital ethics committee.

\section{Diets}

Two different test diets were given to twenty-nine monks for 3 months, each dietary period being separated by 3 months of the subject's usual diet. Both interventional diets (Table 1) provided roughly $8800 \mathrm{~kJ} / \mathrm{d}(2100 \mathrm{kcal} / \mathrm{d}), 11 \% \mathrm{TE}$ of which was from SFA (5.5\% palmitic acid, $2.3 \%$ stearic acid), $15 \%$ from MUFA, $4.5 \%$ from LIA, and $0.9 \%$ from ALA (8\% from PUFA; LIA:ALA ratio 5.2).

Table 1. Nutrient daily intake in control and experimental diets

\begin{tabular}{|c|c|c|c|}
\hline & Control diet & Diet 1 & Diet 2 \\
\hline Energy (kJ) & 8800 & 8800 & 9200 \\
\hline Fat $(\mathrm{g}(\%))$ & $73.3(32 \cdot 0)$ & $77.4(33.0)$ & $85.6(36.0)$ \\
\hline Saturated fat $(g(\%))$ & $24.8(11.0)$ & $24.4(11.0)$ & $29.0(12.0)$ \\
\hline Myristic acid (g (\%)) & $2.9(1.2)$ & $2.9(1.2)$ & $4.0(1.8)$ \\
\hline Palmitic acid (g (\%)) & $12.8(5.5)$ & $12.9(5.5)$ & $13.7(5 \cdot 6)$ \\
\hline Stearic acid $(\mathrm{g}(\%))$ & $5.7(2.4)$ & $5.2(2.4)$ & $5.4(2 \cdot 2)$ \\
\hline Monounsaturated fat (g (\%)) & $30.0(13.0)$ & $32.3(14.0)$ & $35.5(15.0)$ \\
\hline Oleic acid (g (\%)) & $22.6(9.7)$ & $26.3(11.3)$ & $28.3(11.6)$ \\
\hline Polyunsaturated fat (g (\%)) & $19.4(8.0)$ & $17.4(8.0)$ & $17.9(8.0)$ \\
\hline LIA $(g(\%))$ & $12.8(5.5)$ & $10.7(4.6)$ & $10.9(4.5)$ \\
\hline $\operatorname{ALA}(\mathrm{g}(\%))$ & $0.8(0.4)$ & $2.1(0.9)$ & $2.1(0.9)$ \\
\hline EPA & 0.21 & 0.21 & 0.21 \\
\hline $\mathrm{DHA}$ & 0.54 & 0.54 & 0.54 \\
\hline DHA:EPA ratio & 2.57 & 2.57 & 2.57 \\
\hline $\mathrm{P}: \mathrm{S}$ ratio & 0.78 & 0.71 & 0.62 \\
\hline LIA:ALA ratio & $15 \cdot 2$ & $5 \cdot 1$ & $5 \cdot 2$ \\
\hline Cholesterol (mg) & $254 \cdot 0$ & $251 \cdot 0$ & 333.0 \\
\hline Carbohydrate (g (\%)) & $271.6(53.0)$ & $271.6(52.0)$ & $269.0(50.0)$ \\
\hline Protein $(\mathrm{g}(\%))$ & $76.0(15.0)$ & $76.0(15.0)$ & $77.4(14.0)$ \\
\hline Fibre $(\mathrm{g})$ & $27 \cdot 3$ & $27 \cdot 3$ & $27 \cdot 3$ \\
\hline Alcohol (g) & $10 \cdot 0$ & $10 \cdot 0$ & $10 \cdot 0$ \\
\hline Calcium (mg) & 937.5 & 938.9 & $957 \cdot 1$ \\
\hline Vitamin A ( $\mu$ g RE) & $513 \cdot 1$ & $508 \cdot 0$ & $508 \cdot 0$ \\
\hline Vitamin $\mathrm{C}(\mathrm{mg})$ & 62.4 & $62 \cdot 4$ & 62.4 \\
\hline Vitamin E (mg) & $23 \cdot 0$ & $12 \cdot 4$ & $20 \cdot 1$ \\
\hline
\end{tabular}

LIA, linoleic acid; ALA, $\alpha$-linolenic acid, P:S, polyunsaturated:saturated; RE, retinol equivalents.
Intakes of MA were different in the two interventional diets: $1.2 \% \mathrm{TE}$ in diet $1 v .1 .8 \% \mathrm{TE}$ in diet 2 . The sources of fat for the two interventional diets were rapeseed oil $(20 \mathrm{ml} / \mathrm{d}, 60 \%$ of ALA in sn-2 position) and butter $(10 \mathrm{~g} /$ slice) alternating with sunflower margarine ( $10 \mathrm{~g} /$ slice). The MA in diet 1 came from full-cream milk $(200 \mathrm{ml} / \mathrm{d})$, whereas in diet 2 it was obtained from a fractionated crystallisation technique (Lactalis Recherche et Developpement, Rétiers, France). In this experimental condition, the MA content of enriched milk was $7 \cdot 1 \mathrm{~g} / \mathrm{kg}$ v. $3.6 \mathrm{~g} / \mathrm{kg}$ in fullcream milk (two-fold greater); the palmitic and stearic acid contents were $13.6 v .9 .1 \mathrm{~g} / \mathrm{kg}$ and $3.2 v .4 .1 \mathrm{~g} / \mathrm{kg}$, respectively.

Except for cholesterol content, which was higher in diet 2 because of a higher concentration in enriched milk ( 3.7 v. $0.91 \mathrm{~g} / \mathrm{l})$, the intakes of carbohydrates, proteins, Ca and vitamins $\mathrm{A}, \mathrm{E}$ and $\mathrm{C}$ were very similar in the two interventional diets (Table 1). The composition of the diets was evaluated with the Bilnut program. The menus were designed by a dietitian in accordance with the group's eating habits. Food was prepared daily by a monk in the abbey kitchen. As a measure of compliance, the $7 \mathrm{~d}$ intake was analysed once at the end of each diet period to compare the amount of food actually consumed with the amount served.

A control diet, which was the subjects' habitual diet (Table 1), provided $8800 \mathrm{~kJ} / \mathrm{d}(2100 \mathrm{kcal} / \mathrm{d})$ with $32 \%$ from fat, $11 \%$ from SFA ( $1.2 \%$ MA, $5.5 \%$ palmitic acid, $2.4 \%$ stearic acid), $13 \%$ from MUFA and $8 \%$ from PUFA (5.5\% LIA, $0.4 \%$ ALA; LIA:ALA ratio $15 \cdot 2$ ). This habitual diet was consumed before the first intervention diet and for 3 months between diets 1 and 2.

\section{Lipid and fatty acid analysis in plasma}

Fasting blood samples were obtained from all twenty-nine subjects at a baseline visit before the initiation of each interventional period and at the end of the two 3-month nutritional interventions. Blood was collected in EDTA and placed immediately on ice; the plasma was then separated. Total lipids were extracted from plasma with $5 \mathrm{ml}$ hexane-isopropanol (3:2, v/v). Total cholesterol, HDLcholesterol and triacylglycerols were analysed enzymatically using a multiparameter automated analyser LX 20 (Beckman-Coulter, France). LDL-cholesterol was calculated using the Friedewald equation. The apo A-I and apo B were measured in the serum using a turbidimetry method kle LX 20.

The plasma fatty acid composition of the phospholipids and cholesteryl esters was determined from $2 \mathrm{ml}$ lipid extract after transformation into isopropyl esters. The isopropyl esters were separated by GC (CG 500; Thermofinnigan, France) using a $50 \mathrm{~m}$ Carbowax capillary column (internal diameter $0.32 \mathrm{~mm}$ ). Column conditions were $180^{\circ} \mathrm{C}$ for $5 \mathrm{~min}$, increasing by $7.5^{\circ} \mathrm{min}$ to $220^{\circ} \mathrm{C}$ for $30 \mathrm{~min}$. The injector was at $60^{\circ} \mathrm{C}$ and the flame ionization detector was at $250^{\circ} \mathrm{C}$. It was used as the carrier gas (flow rate $2 \mathrm{ml} /$ min). The peaks were identified by comparison with reference fatty acid esters (Sigma), and peak areas were measured with an automatic integrator (DP 700; Fisons Instruments, France). The results of each fatty acid were 
expressed as the percentage of total fatty acids. Fatty acid analyses of enriched and full-cream milks were performed according to the same extraction method, and the results were expressed in $\mathrm{g} / \mathrm{kg}$.

\section{Membrane fluidity analysis}

The technique used was electron spin resonance (Shinitzky, 1982) with a 16-doxylstearate extrinsic paramagnetic probe. $\mathrm{RBC}$ were washed three times in PBS $(0 \cdot 2 \mathrm{M}, \mathrm{pH} 7 \cdot 4)$. They were then labelled with 16-doxylstearate $0.02 \mathrm{M}$ in dimethylsulfoxide. The probe readily incorporated the membrane and labelled the interfacial bilayer area. Cell samples $(200 \mu \mathrm{l})$ were labelled with $2 \mu \mathrm{l}$ probe. All the measures were taken at $24^{\circ} \mathrm{C}$ in order to improve the spectral resolution. The relaxation-correlation time $\left(\tau_{\mathrm{c}}\right)$ of the probe embedded in the bilayers was calculated from spectra obtained with a Bruker electron spin resonance spectrometer ECS106 (Wissembourg, France) equipped with a TMH 259 cavity. The central magnetic field value was 3490 Gauss and the frequency was $9.5 \mathrm{GHz}$. The value of $\tau_{\mathrm{c}}$ was measured in nanoseconds and was directly proportional to the lipid dynamics (i.e. fluidity) according to the Keith equation (Keith et al. 1973):

$$
\tau_{\mathrm{c}}=6 \cdot 510^{-10} \omega\left(\left(\mathrm{H}_{0} / \mathrm{H}_{-1}\right)^{1 / 2}+\left(\mathrm{H}_{0} / \mathrm{H}_{+1}\right)^{1 / 2}-2\right) .
$$

Values $\mathrm{H}_{+1}, \mathrm{H}_{0}$ and $\mathrm{H}_{-1}$ were the heights of spectrum lines, and $\omega_{0}$ was the width of the main line. Data were obtained by calculating the mean of ten spectra per sample. The $\tau_{\mathrm{c}}$ was the time taken by the probe to cover an arc of $1 \mathrm{rad}$ in a cone inside the studied medium (Seelig, 1970). Thus, the lower the value $\tau_{\mathrm{c}}$, the higher the membrane fluidity, and vice versa. The $\tau_{\mathrm{c}}$ depends on the membrane fluidity modulators such as the cholesterol:phospholipid ratio and the nature of the phospholipid fatty acid composition. The presence of cis double bonds enhances fluidity and can be recorded in intact cells labelled with the above probe. The normal range of $\tau_{\mathrm{c}}$ for human erythrocytes is $2 \cdot 8-3 \cdot 8 \mathrm{~ns}$.

\section{Statistical analysis}

The Wilcoxon signed ranks test was used to compare plasma lipid and fatty acid levels, and $P<0.05$ were considered to be significant. Results were expressed as means and standard deviations. Means of separate measurements for each lipid and lipoprotein variable during the control and the two interventional diets were calculated for each subject. All twenty-nine subjects received the control diet for 3 months (measure $\mathrm{T}_{0}$ ), diet 1 for 3 months (measure $\mathrm{T}_{1}$ ), the control diet for 3 months (measure $\mathrm{T}_{2}$ ) and finally diet 2 for 3 months (measure $\mathrm{T}_{3}$ ). Comparisons of $T_{0}$ to $T_{1}, T_{2}$ and $T_{3}, T_{1}$ to $T_{2}$ and $T_{3}$, and $T_{2}$ to $T_{3}$ were made. The results were expressed as a means and standard deviations. Pearson's correlation coefficient was used to measure the associations between serum lipid levels and fatty acids in phospholipids and cholesteryl esters after the two interventional diets.

\section{Results}

\section{Anthropometric parameters}

There was no variation in weight, BMI or blood pressure between the different diets, nor between the beginning and end of the study.

\section{Serum lipids, lipoproteins and apoproteins}

Compared with the control diet, diet 1 was associated with a decrease in total cholesterol $(P<0 \cdot 0001)$, LDL-cholesterol $(P<0.001), \quad$ HDL-cholesterol $\quad(P<0.05), \quad$ triacylglycerols $(P<0.05)$ and apo B $(\mathrm{p}<0.05)$, and in the ratio of total to HDL-cholesterol $(P<0.05 ;$ Table 2$)$. The apo A-I:apo B ratio was higher $(P<0 \cdot 05)$.

Diet 2 was associated with a decrease in triacylglycerols $(P<0.05)$ and in the ratios of total to HDL-cholesterol $(P<0.05)$ and of triacylglycerols to HDL-cholesterol $(P<0.05$; Table 2). HDL-cholesterol $(P<0 \cdot 05)$ and apo A-I levels were higher $(P<0 \cdot 005)$.

Compared with diet 2, diet 1 induced a lower decrease in triacylglycerols $(P<0.005)$ and in the ratio of triacylglycerols to HDL-cholesterol $(P<0 \cdot 05$; Table 2$)$.

\section{Fatty acids of phospholipids and cholesteryl esters}

With regard to phospholipids, diet 1 led to a decrease in levels of MA $(P<0.05)$ and an increase in ALA $(P<0.0001)$, EPA $(P<0.001)$ and DHA $(P<0.05)$. None of palmitic, stearic, oleic, arachidonic or docosapentaenoic acid, or LIA, was modified (Table 3). Diet 2 led to a decrease in the levels of MA $(P<0 \cdot 05)$, EPA $(P<0 \cdot 001)$, docosapentaenoic acid $(P<0.005)$

Table 2. Plasma lipids, lipoproteins and apo after the two interventional diets (Values were means and standard deviations, except for ratios)

\begin{tabular}{|c|c|c|c|c|c|c|c|c|}
\hline & \multicolumn{2}{|c|}{ Control diet (mg/l) } & \multicolumn{2}{|c|}{ Diet 1 (mg/l) } & \multicolumn{2}{|c|}{ Control diet (mg/l) } & \multicolumn{2}{|c|}{ Diet 2 (mg/l) } \\
\hline & Mean & SD & Mean & SD & Mean & SD & Mean & SD \\
\hline Total cholesterol & 2080 & 350 & $1900^{d}$ & 350 & 1980 & 290 & 1980 & 280 \\
\hline LDL-cholesterol & 1380 & 270 & $1250^{c}$ & 280 & 1310 & 230 & 1310 & 220 \\
\hline HDL-cholesterol & 550 & 150 & $520^{a}$ & 140 & 500 & 110 & $530^{a}$ & 110 \\
\hline Triacylglycerols & 730 & 290 & $680^{\mathrm{a}, \mathrm{B}}$ & 320 & 840 & 370 & $780^{a}$ & 340 \\
\hline apo A-I & 1630 & 300 & 1600 & 260 & 1530 & 210 & $1630^{\mathrm{b}}$ & 270 \\
\hline apo B & 1000 & 180 & $950^{\mathrm{a}}$ & 210 & 930 & 170 & 950 & 150 \\
\hline apo A-I:apo B & 1.68 & 0.44 & $1.78^{a}$ & 0.45 & $1 \cdot 70$ & 0.38 & 1.76 & 0.38 \\
\hline Total cholesterol:HDL-cholesterol & 3.99 & 1.01 & $3 \cdot 81^{a}$ & 0.97 & $4 \cdot 12$ & 0.93 & $3.92^{a}$ & 0.94 \\
\hline Triacylglycerols:HDL-cholesterol & 1.53 & 1.01 & $1.44^{\mathrm{A}}$ & 0.90 & 1.84 & 1.05 & $1.65^{a}$ & 0.96 \\
\hline
\end{tabular}


and DHA $(P<0.0001)$, whereas oleic and ALA levels were increased $(P<0.0001)$. None of palmitic, stearic or arachidonic acid, or LIA, was modified (Table 3 ). Compared with diet 2, diet 1 induced a lower decrease in oleic acid $(P<0.0001)$ and a higher increase in EPA $(P<0 \cdot 0001)$, docosapentaenoic acid $(P<0.001)$ and DHA $(P<0.0001$; Table 3$)$.

With regard to cholesteryl esters, diet 1 led to a decrease in the level of LIA $(P<0.05)$ and an increase in ALA $(P<0 \cdot 001)$ and EPA $(P<0 \cdot 001)$. None of myristic, palmitic, stearic, oleic and arachidonic acid, or DHA, were modified (Table 4). Diet 2 led to a decrease in LIA $(P<0.05)$ and EPA $(P<0.001)$ and an increase in oleic acid $(P<0.005)$ and ALA $(P<0.001)$. None of myristic, palmitic, stearic or arachidonic acid, or DHA, were modified (Table 4). Compared with diet 2 , diet 1 led to a lower decrease in oleic acid $(P<0.005)$ and a higher increase in EPA $(P<0.0001$; Table 4).

Stepwise univariate regression showed that MA was positively correlated with ALA in the phosphoplids with diet 1 $(r=0.42, P<0.02)$ and the control diet $(r=0.46, P<0.02)$, but not with diet 2 (Fig. 1).

\section{Membrane fluidity}

In all subjects and irrespective of age, diets 1 and 2 were accompanied by a significant improvement in RBC membrane fluidity $(P<0 \cdot 0001)$ and with a higher fluidity in diet 1 compared with the control diet $(P<0.0001$; Fig. 2). Stratification by age gave superimposable results among those aged above 70 years, those aged between 50 and 70, and those aged under 50, with a higher membrane fluidity for diet 1 $(P<0 \cdot 01)$. The older the subjects, the higher the fluidity obtained from diet $1: 3 \cdot 27,3.38$ and $3.43 \mathrm{~ns}$ among those aged above 70, 50-70 and under 50 years, respectively (Fig. 2).

\section{Discussion}

The aim of the study was to evaluate over 1 year (four 3month periods), the influence on lipid profile and RBC membrane fluidity of two levels of intake of MA $(1.2 \%$ and $1.8 \% \mathrm{TE})$ associated with two intakes of ALA $(0.4 \%$ and $0.9 \% \mathrm{TE}$ ) both mainly in the sn-2 position. During the study, intakes of palmitic, stearic and oleic acid, and LIA, were $5.5 \%, 2.3 \%, 11.5 \%$ and $4.5 \% \mathrm{TE}$, respectively, and the LIA:ALA ratio was 5.1. All these intakes are considered to be desirable (Sandker, 1992; Hu et al. 1999).

In all diets, MA was in the sn-2 position on the triacylglycerol, which is the physiologically active form, is preferentially absorbed by enterocytes in the form of 2-monoglyceride and is immediately bioavailable (Jensen, 1996). Such intakes of MA, represent not more than 10-15\% TE in the form of dairy fat. Interventional studies concerning MA intake have been performed but with inappropriate levels ranging from $10 \%$ to $52 \%$ TE (Tholstrup et al. 1994; Zock et al. 1994; Kris-Etherton \& Yu, 1997; Temme et al. 1997). Very few studies on MA supplements given in appropriate levels to human subjects have been published: Hughes et al. (1996) studied an intake of $8 \mathrm{~g} / \mathrm{d}$ stable-isotope-labelled MA that was $3.6 \%$ TE. Another study (Billeaud et al. 1997; Babin et al. 2000) was carried out in premature neonates with experimental milk enriched with ALA and supplying $1.8 \% \mathrm{TE}$ in the form of MA mainly in the sn-2 position. Intakes of other fatty acids corresponded to levels considered to be neutral (De Lorgeril et al. 1994; Hu et al. 1999).

Diet 1 was associated with a decrease in total cholesterol, LDL-cholesterol, HDL-cholesterol, the ratio of total to HDL-cholesterol, triacylglycerols and apo B. Diet 2 was accompanied by an increase in HDL-cholesterol and apo A-I, and a decrease in triacylglycerols and in the ratio of total to HDL-cholesterol. These results are close to recent data (Mozzafarian et al. 2004) in which the highest SFA quartile was associated with the highest levels of HDL-cholesterol and the lowest levels of triacylglycerols, and with a slower progression of coronary lesions. In the Framingham cohort, an inverse relationship has been shown (Gillman et al. 1997) between SFA and MUFA (but not PUFA) intake and the incidence of ischaemic strokes, the risk decreasing by $9 \%$ for every $1 \%$ increase in SFA. Furthermore, the ratio of total to HDL-cholesterol now seems to be one of the best predictors of vascular risk as it also includes VLDL-cholesterol, which is positively correlated with CHD.

In the present study, the decrease in the ratio of total to HDL-cholesterol (by $6 \%$ ) with intakes of MA of $1.2 \% \mathrm{TE}$ and ALA of $0.9 \%$ TE (diet 1) was associated with a greater

Table 3. Fatty acids in phospholipids after the two interventional diets (Values were mean percentage total fatty acids and standard deviations)

\begin{tabular}{|c|c|c|c|c|c|c|c|c|}
\hline & \multicolumn{2}{|c|}{ Control diet (\%) } & \multicolumn{2}{|c|}{ Diet $1(\%)$} & \multicolumn{2}{|c|}{ Control diet (\%) } & \multicolumn{2}{|c|}{ Diet 2 (\%) } \\
\hline & Mean & SD & Mean & SD & Mean & SD & Mean & SD \\
\hline Myristic acid & $16 \cdot 4$ & 0.40 & $1.47^{\mathrm{a}}$ & 0.25 & 1.64 & 0.40 & $1.46^{\mathrm{a}}$ & 0.36 \\
\hline Palmitic acid & $28 \cdot 26$ & $2 \cdot 26$ & 27.03 & 1.75 & $27 \cdot 53$ & 1.43 & $27 \cdot 55$ & 1.83 \\
\hline Stearic acid & $10 \cdot 43$ & 2.43 & $11 \cdot 13$ & 2.78 & $10 \cdot 85$ & 2.44 & $10 \cdot 20$ & 1.74 \\
\hline Oleic acid & $19 \cdot 24$ & 2.43 & $19 \cdot 08^{\mathrm{D}}$ & $2 \cdot 25$ & $19 \cdot 38$ & $2 \cdot 17$ & $20 \cdot 97^{d}$ & 2.46 \\
\hline Linoleic acid & $29 \cdot 88$ & $2 \cdot 88$ & $29 \cdot 71$ & $2 \cdot 89$ & 29.84 & 2.57 & $29 \cdot 40$ & $3 \cdot 82$ \\
\hline Arachidonic acid & 5.45 & 0.98 & 5.54 & 0.91 & $5 \cdot 54$ & 0.80 & $5 \cdot 83$ & 1.25 \\
\hline$\alpha$-Linolenic acid & 0.62 & 0.15 & $0.87^{d}$ & 0.22 & 0.62 & 0.15 & $0.82^{d}$ & 0.23 \\
\hline EPA & $1 \cdot 23$ & 0.50 & $1 \cdot 75^{c, D}$ & 0.55 & 1.48 & 0.36 & $1 \cdot 16^{c}$ & 0.29 \\
\hline Docosapentaenoic acid & 0.52 & 0.11 & $0.56^{\mathrm{C}}$ & 0.14 & 0.53 & 0.11 & $0.46^{\mathrm{b}}$ & 0.12 \\
\hline $\mathrm{DHA}$ & $2 \cdot 73$ & 0.46 & $2 \cdot 86^{a, D}$ & 0.62 & $2 \cdot 76$ & 0.52 & $2 \cdot 28^{d}$ & 0.45 \\
\hline
\end{tabular}

Means with unlike superscript letters were signficantly different from the control $\operatorname{diet}\left({ }^{\mathrm{a}} P<0.05,{ }^{\mathrm{b}} P<0.005,{ }^{\mathrm{c}} P<0.001,{ }^{\mathrm{d}} P<0.0001\right)$ or $\operatorname{diet} 1\left({ }^{\mathrm{C}} P<0.001\right.$, $\left.{ }^{\mathrm{D}} P<0.0001\right)$. 
Table 4. Fatty acids in cholesteryl esters after the two interventional diets

(Values were mean percentage total fatty acids and standard deviations)

\begin{tabular}{|c|c|c|c|c|c|c|c|c|}
\hline & \multicolumn{2}{|c|}{ Control diet (\%) } & \multicolumn{2}{|c|}{ Diet 1 (\%) } & \multicolumn{2}{|c|}{ Control diet (\%) } & \multicolumn{2}{|c|}{ Diet $2(\%)$} \\
\hline & Mean & SD & Mean & SD & Mean & SD & Mean & SD \\
\hline Myristic acid & 1.53 & 0.48 & 1.46 & 0.40 & 1.53 & 0.31 & 1.48 & 0.55 \\
\hline Palmitic acid & $17 \cdot 88$ & $3 \cdot 35$ & $17 \cdot 54$ & $2 \cdot 81$ & $17 \cdot 48$ & $3 \cdot 20$ & $18 \cdot 53$ & 3.80 \\
\hline Stearic acid & 7.04 & 3.52 & $8 \cdot 77$ & $5 \cdot 81$ & $8 \cdot 20$ & $4 \cdot 15$ & $7 \cdot 32$ & $5 \cdot 14$ \\
\hline Oleic acid & $20 \cdot 41$ & 4.76 & $20 \cdot 22^{\mathrm{B}}$ & 4.99 & $20 \cdot 31$ & 4.72 & $22.91^{b}$ & 5.45 \\
\hline Linoleic acid & 45.95 & $7 \cdot 11$ & 42.94 & $8 \cdot 16$ & $45 \cdot 58$ & $5 \cdot 73$ & $42 \cdot 33^{a}$ & $7 \cdot 39$ \\
\hline Arachidonic acid & 4.43 & 0.92 & 4.57 & 0.97 & 4.56 & 0.82 & 4.66 & 1.06 \\
\hline$\alpha$-Linolenic acid & 0.65 & 0.27 & $0.86^{c}$ & 0.31 & 0.65 & 0.28 & $0.86^{c}$ & 0.40 \\
\hline EPA & $1 \cdot 27$ & 0.37 & $1.57^{\mathrm{C}, \mathrm{D}}$ & 0.39 & 1.42 & 0.33 & $1 \cdot 15^{c}$ & 0.34 \\
\hline $\mathrm{DHA}$ & 0.83 & 0.41 & 0.94 & 0.72 & 0.84 & 0.54 & 0.75 & 0.39 \\
\hline
\end{tabular}

Means with unlike superscript letters were signficantly different from the control diet $\left({ }^{\mathrm{a}} P<0.05,{ }^{\mathrm{b}} P<0.005,{ }^{\mathrm{c}} P<0.001\right)$ or $\operatorname{diet} 1\left({ }^{\mathrm{B}} P<0.005\right.$, $\left.{ }^{\mathrm{D}} P<0.0001\right)$

decrease in total cholesterol and LDL-cholesterol (falls of $9 \%$ and $10 \%$, respectively) than HDL-cholesterol (6\% decrease). On the other hand, with intakes of $1.8 \% \mathrm{TE}$ of MA and $0.9 \% \mathrm{TE}$ of ALA (diet 2), the decrease in the ratio of total to HDL-cholesterol (of $5 \%$ ) was solely due to an increase in HDL-cholesterol (6\% rise).

Diet 1 led to an increase in ALA, EPA and DHA in phospholipids and cholesteryl esters. Diet 2 induced an increase in ALA in both phospholipids and cholesteryl esters, whereas EPA, docosapentaenoic acid and DHA were decreased in phospholipids, only EPA was lower in cholesteryl esters. Two previous studies of shorter duration (Dabadie et al. 2004, 2005) have already shown an increase in ALA, EPA and DHA in phospholipids and cholesteryl esters for intakes of MA of $1.2 \%$ and $1.8 \% \mathrm{TE}$ (ALA intakes at $0.9 \% \mathrm{TE}$ being identical in all three studies). The rise in ALA with the experimental diets may be explained by intakes of more than two-fold those in the control diet: 0.9 v. 0.4\%TE. Indeed, many studies (Billeaud et al. 1997; Babin et al. 2000; Combe et al. 2002; Dabadie et al. 2004) have clearly shown a positive correlation between intake and the percentage of ALA in cholesteryl esters. In addition, a positive correlation between MA and ALA in phospholipids only with diet 1 points to a specific metabolic channel for these two fatty acids at these levels: both were in the sn- 2 position on the triacylglycerol, which protects them against $\beta$-oxidation.

An increase in ALA might partly explain the increase in the higher $n$ - 3 derivates observed with diet 1 , which resulted from the conversion of ALA through the $\Delta 6$ and $\Delta 5$ desaturases.
Furthermore, it has recently been shown in rat hepatocyte cultures that the activity of $\Delta 6$ desaturase can be increased by MA (but not by lauric or palmitic acid) in a dose-dependent manner (Jan et al. 2004). Considering enzymatic activity, direct acylation of the $\Delta 6$ desaturase by MA could occur as rat $\Delta 6$ desaturase exhibits a potential site of myristoylation (the amino-terminal glycine). Myristoylation of the amino-terminal glycine of NADH cytochrome $b_{5}$ reductase is of a co-transcriptional type and could also account for the change in activity of the whole complex of $\Delta 6$ desaturation (Borgese et al. 1996).

RBC membrane fluidity was very significantly increased among all the subjects with both diets. The best results were obtained among the oldest subjects with diet 1 , their membrane fluidity increasing by about $30 \%$ (from 4.17 to $3.27 \mathrm{~ns}$ ). The average normal $\tau_{\mathrm{c}}$ for human RBC is between 2.8 and $3.8 \mathrm{~ns}$, and a difference of $0.4-0.5 \mathrm{~ns}$ is usually considered significant (Shinitzky, 1982). Parameters associated with the membrane such as plasticity, deformability and stress resistance were improved when its fluidity was optimised. Thus, all these modifications could have beneficial effects on cerebral vascularisation and could decrease the incidence of stroke. In addition, the improvement of membrane fluidity might be associated with an enhancement of the granulocyte and mononuclear membrane, whose role in atheromatous inflammation is well known (Wallace et al. 2003; Rees et al. 2006).

These data confirm our previous results obtained in two 5-week studies (Dabadie et al. 2004, 2005). When the intake of MA increased from $1.2 \%$ to $1.8 \% \mathrm{TE}$, beneficial
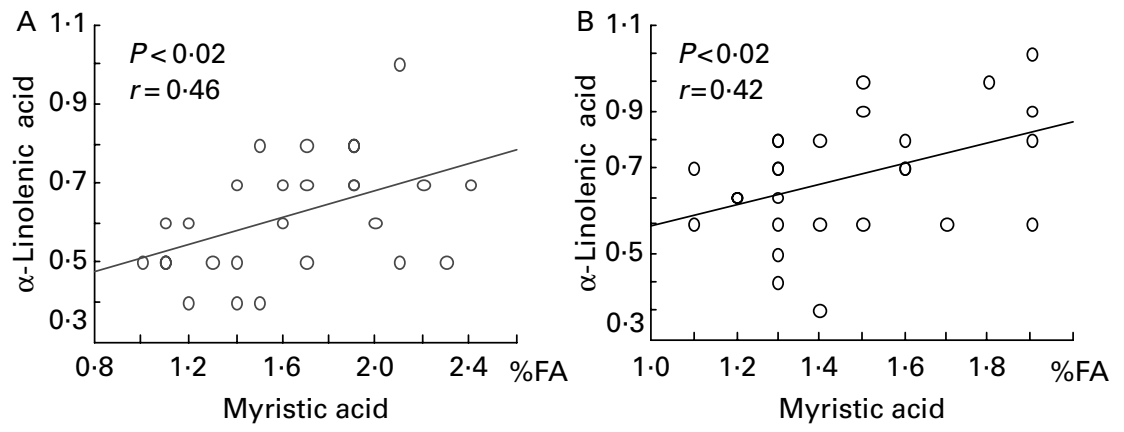

Fig. 1. Correlation between phospholipid myristic and $\alpha$-linolenic acids in (A) the control diet and (B) diet 1. FA, fatty acid. 


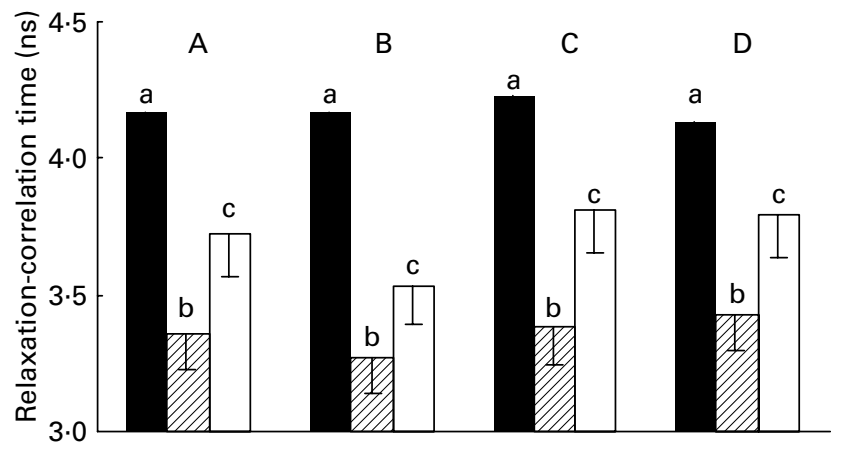

Fig. 2. Red blood cell membrane fluidity after the two experimental diets: (A) all ages; (B) subjects over 70 years old; (C) those aged 50-70 years; (D) those under 50 years old. Means with unlike superscript letters were significantly different at $P<0.001$. The shorter the relaxation-correlation time, the higher was the membrane fluidity. $\mathbf{\square}$, Control diet; $\llbracket$, diet $1 ; \square$, diet 2 .

lipidic effects were partially lost even if ALA intake was at recommended level (0.9\%TE). This suggests the existence of a U-shaped curve for MA with a favourable turning point at around $1.2 \% \mathrm{TE}$. Contrary to what is often published, as among premature neonates, ALA is indeed transformed to DHA through a synergy between MA in the sn-2 position and ALA in the sn-2 position at physiological levels. The U-curve and synergistic effects were also found for RBC membrane fluidity. Our most recent data obtained in the same population point to a spectacular synergistic effect on plasma lecithin cholesterol acyltransferase activity (Dabadie $\mathrm{H} \&$ Combe $\mathrm{N}$ unpublished results). We now intend to establish correlations between the structure and composition of RBC membrane lipids and their fluidity.

\section{Acknowledgements}

The authors are indebted to CERIN, Paris (France), Lactalis Recherche et Développement (Rétiers, France) and the Benedictine monks from Randol (France). None of the authors had any financial or personal conflict of interest. H. D. was supported by a grant from CNIEL, Paris, France.

\section{References}

Ascherio A, Rimm EB, Giovannucci EL, Spiegelman D, Stampfer M \& Willett WC (1996) Dietary fat and risk of coronary heart disease in men: cohort follow up study in the United States. BMJ 313, 84-90.

Babin F, Rodriguez A, Sarda P, Vandeputte B, Mendy F \& Descomps B (2000) Alpha linolenic acid in cholesterol esters: a marker of alphalinolenic acid intake in newborns. Eur J Clin Nutr 54, 840-843.

Billeaud C, Bougle D, Sarda P, Combe N, Mazette S, Babin F, Entressangles B, Descombs B, Nouvelot A \& Mendy F (1997) Biological effects of preterm infant formula supplementation with $\alpha$-linolenic acid with a linoleate/ $\alpha$-linolenate ratio of 6 : a multicentric study. Eur J Clin Nutr 51, 520-526.

Borgese N, Aggujaro D, Carrera P \& Bassetti M (1996) A role for $\mathrm{N}$-myristoylation in protein targeting: NADH-cytochrome $\mathrm{b}_{5}$ reductase requires myristic acid for association with outer mitochondrial but not ER membranes. J Cell Biol 135, $1501-1513$.

Clandinin MT, Cook SL, Konard SD \& French MA (2000) The effect of palmitic acid on lipoprotein cholesterol levels. Int J Food Sci and Nutr 51, S61-S71.

Combe N, Delplanque B, Tanguy S, Boué C, Mendy F, LeRoy B \& Fénart E (2002) Alpha-linolenic acid in plasma cholesterol esters, a marker of alpha-linolenic intake in humans. OCL 9, $245-248$.

Dabadie H, Peuchant E, Bernard M, LeRuyet P \& Mendy F (2005) Moderate intake of myristic acid in sn-2 position has beneficial lipidic effects and enhances DHA of cholesteryl esters in an interventional study. J Nutr Biochem 16, 375-382.

Dabadie H, Peuchant E, Bernard M \& Mendy F (2004) Physiological intakes of myristic acid from milk improve lipid profile. Lipid Technology 16, 149-152.

De Lorgeril M, Renaud S, Mamelle N, Salen P, Martin JL, Monjaud I, Guidollet J, Touboul P \& Delaye J (1994) Mediterranean alphalinolenic acid-rich diet in secondary prevention of coronary heart disease. Lancet 343, 454-459.

Gillman MW, Cupples LA, Millen BE, Ellison RC \& Wolf PA (1997) Inverse association of dietary fat with development of ischemic stroke in men. JAMA 278, 2145-2150.

Hu FB, Stampfer MJ, Manson JE, Ascherio A, Colditz GA, Speizer FE, Hennekens CH \& Willett WC (1999) Dietary saturated fats and their food sources in relation to the risk of coronary heart disease in women. Am J Clin Nutr 70, 1001-1008.

Hughes TA, Heimberg M, Wang X, Wilcox H, Hughes SM, Tolley EA, Desiderio DM \& Dalton JT (1996) Comparative lipoprotein metabolism of myristate, palmitate and stearate in normolipidemic men. Metabolism 45, 1108-1118.

Jan S, Guillou H, D'Andrea S, Daval S, Bouriel M, Rioux V \& Legrand P (2004) Myristic acid increases $\Delta 6$-desaturase activity in cultured rat hepatocytes. Reprod Nutr Dev 44, $131-140$.

Jensen RG (1996) The lipids in human milk. Prog Lipid Res 35, 53-92.

Keith A, Sharvoff M \& Cohn GE (1973) A summary and evaluation of spin labels used as probes of biological membrane structure. Biochem Biophys Acta 300, 379-419.

Keys A (1980) Seven Countries: A Multivariate Analysis of Death and Coronary Heart Disease. Cambridge, MA: Harvard University Press.

Krauss RM, Eckel RH, Howard B et al. (2000) AHA dietary guidelines. Circulation 102, 2284-2306.

Kris-Etherton PM \& Yu S (1997) Individual fatty acid effects on plasma lipids and lipoproteins: human studies. Am J Clin Nutr 65, 1628S-1644S.

Mensink RP, Zock PL, Kester ADM \& Katan MB (2003) Effects of dietary fatty acids and carbohydrates on the ratio of serum total to HDL cholesterol and on serum lipids an apoliproteins: a meta-analysis of 60 controlled trials. Am J Clin Nutr 77, $1146-1155$.

Mozzafarian D, Rimm EB \& Herrington DM (2004) Dietary fats, carbohydrate, and progression of coronary atherosclerosis in postmenopausal women. Am J Clin Nutr 80, 1175-1184.

Rees D, Miles EA, Banerjee T, Wells SJ, Roynette CE, Wahle KWJ \& Calder PC (2006) Dose-related effects of eicosapentaenoic acid on innate immune function in healthy humans: a comparison of young and older men. Am J Clin Nutr 83, 331-342.

Sandker GW (1992) Serum cholesteryl ester fatty acids and their relation with serum lipids in elderly men in Crete and the Netherlands. Eur J Clin Nutr 47, 201-208.

Seelig J (1970) Spin label studies of oriented liquid crystals (a model system for bilayer membranes). J Am Chem Soc 92 , 3881-3887.

Shinitzky M (1982) Membrane fluidity and cellular functions. In Physiology of Membrane Fluidity, pp. 1-52 [M Shinitzky, editor]. Boca Raton, FL: CRC Press. 
Temme EH, Mensink RP \& Hornstra G (1997) Effects of medium chain fatty acids (MCFA), myristic acid, and oleic acid on serum lipoproteins in healthy subjects. J Lipid Res 38, 1746-1754.

Tholstrup T, Marckmann P, Jespersen J \& Sandström B (1994) Fat high in stearic acid favorably affects blood lipids and factor VII coagulant activity in comparison with fats high in palmitic acid or high in myristic and lauric acids. Am J Clin Nutr 59, $371-377$.
Wallace FA, Miles EA \& Calder PC (2003) Comparison of the effects of linseed oil and different doses of fish oil on mononuclear cell function in healthy human subjects. Br J Nutr 89, 679-689.

Wang S \& Koo SI (1993) Plasma clearance and hepatic utilization of stearic, myristic and linoleic acids introduced via chylomicrons in rats. Lipids 28, 697-703.

Zock P, de Vries J \& Katan M (1994) Impact of myristic acid versus palmitic acid on plasma lipids and lipoprotein levels in healthy women and men. Arterioscler Thromb 14, 567-575. 